\title{
ENTREVISTA
}

\section{La masonería en el Campo de Gibraltar durante el primer tercio del siglo XX (1902-1936)}

El investigador Antonio Morales Benítez ha defendido una Tesis doctoral, cuyo título es "La masonería en el Campo de Gibraltar durante el primer tercio del siglo XX (19021936)” en la Universidad de Cádiz en España, el 8 de enero de 2016, bajo la dirección de Alberto Ramos Santana. Antonio Morales Benítez nació en 1957 en Ubrique (Cádiz).

El autor nos ha concedido la siguiente entrevista.

¿Cuáles fueron los motivos que le llevó a enfocar su investigación hacia la Masonería?

Es un tema al que llevo dedicándome desde el año 1987 cuando presenté una comunicación al Symposium del CEHME celebrado ese año en Córdoba. Desde entonces no he dejado de acudir a estos encuentros científicos, donde siempre he recibido palabras de apoyo y aliento para continuar con mis investigaciones. Sin duda la existencia de este centro ha sido fundamental para decantarme por este aspecto de la historia. Paralelamente a ello hemos ido publicando otros estudios sobre esta materia en diferentes medios hasta que hemos considerado que hacía falta una obra de conjunto del fenómeno masónico en esta zona gaditana.

¿Cuáles fueron las fuentes que ha utilizado?

Fundamentalmente las procedentes del Centro Documental de la Memoria Histórica de Salamanca, que ha sido la base de la investigación. También el Archivo Histórico Nacional y el Archivo Histórico Provincial de Cádiz. También a nivel más local los archivo municipales de Algeciras, San Roque, La Línea y Tarifa. Asimismo hemos tenido acceso a la documentación existente en Gibraltar: Masonic Institute y el Archive, Convent Courtyard, Secretary's.

¿Cuáles fueron las principales dificultades con las que se ha encontrado? ¿Cómo las ha superado?

No resulta nada fácil el estudio de un fenómeno tan complejo en la provincia de Cádiz, con dinámicas diferentes en cada zona. Sólo el volumen de la documentación existente en Salamanca hace que su consulta sea por si sola una tarea ingente. Hemos optado por acometer el estudio por comarcas. Desde esta perspectiva comarcal, acometer el estudio del 
Campo de Gibraltar, reconstruyendo su estructura interna, era otro gran reto y una problemática histórica por esa complejidad y una gran cantidad de talleres masónicos dentro de una pluralidad de federaciones. Por eso se consideró prioritario confeccionar el mapa masónico y el censo de masones. Durante este período llegaron a trabajar en la comarca 30 talleres y hemos identificado a 1.518 masones, lo que vendría a representar más o menos el 25 por ciento de toda Andalucía.

¿Cuáles fueron las principales problemáticas históricas que su trabajo ha resuelto?

Creo que hemos confirmado la relevancia e importancia histórica que tuvo la masonería en la comarca, así como las estrechas relaciones masónicas entre Gibraltar y su Campo que puede arrojarnos algunas respuestas a numerosos interrogantes debido a la influencia que siempre ejerció la colonia.

Por otra parte, la masonería tuvo en una comarca habitualmente ignorada por los autoridades de la nación una notable dimensión política y social. También hay que destacar su aspecto formativo y cultural, así como su contribución a la potenciación de la sociedad civil en aras de la creación de una ciudadanía democrática. Asimismo, llegó suplir al Estado en la prestación de numerosos servicios.

¿Por favor, podría resumir la esencia de su Tesis en dos líneas?

Hemos querido centrar la masonería en un marco histórico y sociológico amplio, abierto a múltiples enfoques, estableciendo constantemente conexiones con su contexto político, económico, social, cultural e ideológico. Desde esta perspectiva hemos intentado aproximarnos a desentrañar el significado histórico de esta institución.

¿Cuáles fueron las lecciones, a todos los niveles, personal y profesional, que usted ha deducido de su experiencia investigativa?

Considero que, tanto a nivel personal como profesional, ha sido un privilegio haber contribuido en algo a recuperar la memoria de esos más de 1.500 masones. A ellos de debe que este no haya sido en ningún momento un frío trabajo de investigación.

¿Ahora, cuáles son sus proyectos profesionales?

Continuar haciendo lo que me gusta, la tarea investigadora ha sido mi vocación desde hace más de 30 años y espero seguir así mucho tiempo. Siempre la ha compaginado con mi trabajo de profesor de la enseñanza pública. 
¿Quisiera destacar algún aspecto que no se ha contemplado y que usted consideraría digno de reseñar?

He dejado atrás muchos aspectos que no he podido profundizar, como los aspectos socioprofesionales y un estudio comparativo con otros ámbitos, como la ciudad de Cádiz. Tampoco hemos encontrado la ocasión para el estudio de la simbología masónica. Asimismo, la investigación sobre la Orden en Gibraltar queda circunscrita a los talleres de obediencia española. Todo ello son asuntos que dejamos pendientes y a los que habrá que volver.

Esta entrevista se efectúo de forma telemática el 12 de marzo de 2016.

Autores de la entrevista: Ricardo Martínez Esquivel e Yván Pozuelo Andrés, Director y Editor de REHMLAC+.

DOI: http://dx.doi.org/10.15517/rehmlac.v8i1.24274 